\title{
INCUBADORA TECNOLÓGICA DE CAXIAS DO SUL: INOVAÇÃO TECNOLÓGICA SOB A PERSPECTIVA DA HÉLICE TRÍPLICE
}

\author{
CAXIAS DO SUL TECHNOLOGY INCUBATOR: \\ TECHNOLOGICAL INNOVATION THROUGH \\ THE TRIPLE HELIX
}
Recebido em: 05/12/2013 - Aprovado em: 24/02/2014 Avaliado pelo sistema double blind review Editora Científica: Manolita Correia Lima

\author{
PRISCILA BRESOLIN TISOTT priscila.tisott@gmail.com \\ DANIELE NESPOLO \\ DEISE TAIANA DE ÁVILA DIAS \\ PELAYO MUNHOZ OLEA \\ GABRIEL SPERANDIO MILAN \\ UNIVERSIDADE DE CAXIAS DO SUL
}

\begin{abstract}
RESUMO
O objetivo deste estudo foi identificar como o conceito da Hélice Tríplice está aplicado nas atividades da Sociedade Incubadora Tecnológica de Caxias do Sul. Para atingir este objetivo, foram realizadas entrevistas semiestruturadas em profundidade com a ITEC, a Universidade de Caxias do Sul, Câmara da Indústria, Comércio e Serviços de Caxias do Sul, Prefeitura de Caxias do Sul e Comlink Equipamentos Eletrônicos, uma das empresas que obteve êxito na incubação. A análise do conteúdo dos resultados mostrou que a atuação dos agentes se dá, principalmente, por meio de recursos financeiros. Já os principais benefícios obtidos pela Universidade com base nessa relação são o retorno do investimento realizado sob a forma de patentes formalizadas, conquista de novos alunos e reconhecimento como uma Universidade tecnológica, empreendedora e inovadora. Os benefícios percebidos pelo setor industrial são a capacitação das empresas e empreendedores, enquanto o Poder Público Municipal percebe como benefícios a redução na mortalidade das empresas e a geração de retorno financeiro sob a forma de impostos. As conclusões mostram que o conceito da Hélice Tríplice, desenvolvido por Etzkowitz (2009), constitui uma forma de atuação cooperativa e participativa na Incubadora Tecnológica, ainda que mais segmentos da sociedade pudessem ser atendidos.

Palavras-chave: inovação tecnológica; Hélice Tríplice; incubadora de empresas.
\end{abstract}

\section{ABSTRACT}

The aim of this study was to identify how the Triple Helix concept is applied in the activities of the Caxias do Sul Society of Technology Incubation. To achieve this goal, semi-structured in-depth interviews were conducted at ITEC, the University of Caxias do Sul, Chamber of Industry, Commerce and Services of Caxias do Sul, Caxias do Sul City Hall and Comlink Electronic Equipments, one of the companies that was successfully incubated. Content analysis of the results showed that the agents act mainly through the provision of financial resources. Furthermore, the main benefits obtained by the University from this relationship are the return on investment in the form of registered patents, attracting new students and recognition as a technological, entrepreneurial and innovative university. The perceived benefits for the industrial sector are training and development for businesses and entrepreneurs, while the municipal government perceives the reduced number of businesses failing and the financial returns, in the form of taxes, as benefits. The findings show that the Triple Helix concept developed by Etzkowitz (2009) plays a cooperative and participatory role in the Technology Incubator, even though it could be applied to more segments of society.

Keywords: technological innovation; Triple Helix; business incubators. 


\section{INTRODUÇÃO}

A atividade científica tem sofrido alterações em resposta às grandes mudanças socioeconômicas (REIS, 2008), ao mesmo tempo em que essas modificações influenciaram fortemente a consolidação de um novo paradigma, no qual, a globalização da economia leva o setor produtivo a realizar esforços na busca da competitividade (MINISTÉRIO DA CIÊNCIA E TECNOLOGIA, 2000). No Brasil, existe um movimento oriundo do governo central, o qual pretende buscar formas de inovação tecnológica, a fim de garantir o desenvolvimento sócio-econômico e articular as demandas do setor produtivo às atividades de ciência e tecnologia (ETZKowitz; MELLO; ALMEIDA, 2005).

O modelo da Hélice Tríplice, desenvolvido por Etzkowitz (2009), sugere que a chave para a inovação e o crescimento de uma economia baseada no conhecimento está na interação entre a universidade, indústria e governo. Como dispositivo físico, esse modelo pode ser aplicado às economias por meio das empresas de capital de risco, dos parques científicos e das incubadoras de empresas.

Desta forma, com o intuito de integrar os setores industrial e acadêmico no Brasil, surgiu o movimento pela implantação das incubadoras de empresas, as quais constituem um mecanismo de estímulo à criação e ao desenvolvimento de micro e pequenas empresas industriais ou de prestação de serviços, de base tecnológica ou manufaturas leves. Esse processo se dá por meio da capacitação dos empreendedores, que, geralmente, são pessoas sem educação formal (MINISTÉRIO DA CIÊNCIA E TECNOLOGIA, 2000).

A Sociedade Incubadora Tecnológica de Caxias do Sul surgiu no ano de 1999 e, desde então, graduou 35 empresas por meio de seu processo de incubação. Desta forma, o que motivou este estudo foi a necessidade de compreender a verdadeira contribuição da Universidade, do Poder Público Municipal e dos órgãos representativos das indústrias a esta sociedade, tendo em vista que a literatura encontrada acerca do conceito da Hélice Tríplice sugere que estas três dimensões são beneficiadas com base neste tipo de iniciativa de inovação. 
Baseado no exposto, este estudo pretende identificar como o conceito da Hélice Tríplice está aplicado nas atividades da Sociedade Incubadora Tecnológica de Caxias do Sul (ITEC), por meio da óptica da Universidade de Caxias do Sul (UCS), da Prefeitura Municipal de Caxias do Sul, da Câmara de Indústria, Comércio e Serviços de Caxias do Sul (cic) e de uma empresa graduada pela incubadora. 


\section{INOVAÇÃO TECNOLÓGICA}

Drucker (2002) identifica a inovação como um meio utilizado pelas empresas para propor ao mercado algum negócio ou serviço diferente, pretendendo melhorar o desempenho e reduzir custos operacionais (BARBIERI, 2003). Já Schumpeter (1985) aponta a inovação como uma das responsáveis pelo alcance de lucros diferenciados pelas empresas, no momento em que estas conquistam poder competitivo semelhante ao de monopólio. E complementa:

Quando se olha a economia com uma visão estática e se vê uma única empresa no mercado, se associam os lucros extraordinários que possa estar obtendo ao exercício do poder monopolístico que desfruta, à custa dos consumidores. Se olharmos, porém, dinamicamente, essa colocação única de mercado pode se dever à introdução de algo novo na atividade econômica e, portanto, é uma posição passageira. Os lucros maiores que lhe são devidos proveem de inovações, cujos ganhos desaparecem com o ingresso de novos competidores. A questão não é como o sistema administra ditas estruturas, mas como ele as cria e as destrói (sCHUMPETER, 1985).

Produzido pela Organização para Cooperação e Desenvolvimento Econômico (OCDE), o Manual de Oslo tem a finalidade de conceituar, orientar, apresentar indicadores e padrões no âmbito de inovação, tecnologia, pesquisa e desenvolvimento. Este documento expõe a seguinte definição para inovação:

É a implantação de um produto (bem ou serviço) novo ou significativamente melhorado, ou um processo, ou um novo método de marketing, ou um novo método organizacional nas práticas de negócios, na organização do local de trabalho ou nas relações externas (OCDE, 2005).

São diversas as tipologias de inovação apresentadas por pesquisadores da área, contudo, todos concordam que a inovação trata de processos relacionados ao desenvolvimento organizacional (OCDE, 2005). Na óptica da inovação tecnológica, Snell (2006) discorre que a inovação está relacionada ao uso de novas tecnologias e novos processos.

O Manual de Oslo, em sua edição de 1997, menciona uma relevante observação à ampliação do conceito de inovação, quando esta é proveniente de inovação tecnológica de produto e de processo: 
Inovações tecnológicas de produto e de processo (TPP) compreendem a implantação de produtos e de processos tecnologicamente novos e a realização de melhoramentos tecnológicos significativos em produtos e processos. Uma inovação tecnológica de produto e de processo foi implantada se ela foi introduzida no mercado (inovação de produto) ou usada em um processo de produção (inovação de processo) (OCDE/EUROSTAT, 1997, in OCDE, 2005).

De acordo com o Manual de Frascati (ocDE, 2002), a inovação científica e tecnológica pode ser mencionada como a transformação de uma ideia em um produto vendável, seja novo ou melhorado, ou em um processo operacional, da indústria ou do comércio, ou, ainda, em um novo método de serviço social.

A inovação tecnológica pode ser interpretada como a adoção de conhecimentos científicos, técnicos e procedimentos variados para conquistar, comercializar ou fazer uso de novos produtos ou processos (DONADIO, I983). Assim, ela pode resultar em vantagem competitiva se apresentar desempenho expressivo na determinação do custo relativo e da diferenciação (PORTER, I99I).

Abordando a inovação como um processo baseado no conhecimento, Tidd, Bessant e Pavitt (2008, p. 35) sugerem a seguinte interpretação para a inovação: A inovação é uma questão de conhecimento - criar novas possibilidades por meio da combinação de diferentes conjuntos de conhecimentos. Estes podem vir na forma de conhecimento sobre o que é tecnicamente possível ou de que configuração pode responder a uma necessidade articulada ou latente.

Em 2004, foi aprovada a Lei 10.973 no Brasil, estabelecendo medidas de incentivo à inovação e à pesquisa científica e tecnológica no ambiente produtivo, com vistas à capacitação e ao alcance da autonomia tecnológica e ao desenvolvimento industrial do país. Em outras palavras, a chamada Lei de Inovação Tecnológica, tem o objetivo de promover a interação empresaacademia. Por força desta lei, todas as universidades públicas federais devem criar Núcleos de Inovação Tecnológica, para fomentar o gerenciamento de intangíveis das instituições e a transferência de tecnologia.

Siqueira (2007) identifica a inovação como fio condutor para a transferência de tecnologia das intenções de ensino e pesquisa. A aprendizagem, a inovação e conhecimento direcionam o desenvolvimento econômico, ao 
passo que as universidades desenvolvem, armazenam e transmitem o conhecimento, tornando-o mais acessível (BENNEWORTH; DAWLEY, 2005).

É possível identificar o processo inovador entre universidades e empresas ao passo que juntas elas procuram por soluções, emergindo, assim, oportunidades de inovação (ZEN; POSSAS; SANTIN; 2006). Etzkowitz (2009) reforça este pensamento afirmando que a interação entre universidade, indústria e governo é a chave para a inovação e o crescimento de uma economia baseada no conhecimento.

Christensen (200I) reflete em uma abordagem inicial que empresas precisam tomar, de forma inconfundível, posturas diferentes, dependendo de estar direcionadas para uma tecnologia de ruptura ou para uma tecnologia incremental, afirmando que este tipo de ação implica vantagens significativas para os pioneiros. Anos mais tarde, o autor complementa sua colocação ao relatar que:

A estrutura de motivação/capacidade sugere que a inovação floresce quando as empresas dispõem tanto da motivação quanto da capacidade de inovar. Os contextos de mercado deficientes em motivação ou restritos em capacidade estão reprimindo as inovações. As empresas que trazem inovações recentes para ambientes desfavoráveis de mercado terminam ou procurando ambientes mais favoráveis ou abandonando seus esforços. [...] Tanto o governo quanto outros parceiros alheios ao mercado podem afetar a motivação e a capacidade das empresas que participam do setor. Assim fazendo, elas podem mudar o contexto de um setor, tornando-o mais ou menos aberto à inovação (CHRISTENSEN; ANTHONY; ROTH, 2007). 


\section{HÉLICE TRÍPLICE}

Em 1968, Jorge Sábato e Natalio Botana propõem uma abordagem da ciência e tecnologia no intuito de superar o subdesenvolvimento da América Latina. O modelo apresentando, conforme os autores, seria o resultado da ação múltipla e coordenada de três elementos fundamentais para o desenvolvimento social: o governo, a estrutura produtiva e a infraestrutura científica e tecnologia (sÁbATo; вотANA, I968).

Plonski (I998) apresenta os três tipos de relações existentes entre os elementos do chamado Triângulo de Sábato:

1. Intra-relações: relações entre componentes de um mesmo vértice;

2. Inter-relações: relações entre componentes de vértices diferentes;

3. Extra-relações: relações entre um dos elementos e o exterior (câmbio científico, comércio de tecnologia, transformação de tecnologia).

Os estudos nesta perspectiva de vincular a universidade com a empresa seguem até o modelo da Hélice Tríplice, proposto por Etzkowitz e Leydesdorff em i996. Este modelo é baseado na óptica da Universidade como promotora das relações com as Empresas (setor produtivo de bens e serviços) e o Governo (setor regulador e fomentador da atividade econômica), com a intenção de produzir novos conhecimentos, fomentar a inovação tecnológica e fortalecer o desenvolvimento econômico (ETZKOWITZ; LEYDESDORFF, 2000). Neste estudo, o modelo da Hélice Tríplice foi conceituado, principalmente, com base na pesquisa de Etzkowitz (2009), tendo em vista que este autor é o maior pesquisador deste assunto e os resultados de suas pesquisas contemplam as relações entre as dimensões de forma exaustiva.

A universidade está ampliando suas atividades para além dos modelos tradicionais de atuação, ao passo que apresenta capacidade de pesquisa e ensino aliado ao avanço da ciência e da tecnologia. Neste modelo, capitalizase o conhecimento e os pesquisadores e cientistas passam a melhor utilizar os resultados de suas pesquisas. E é neste contexto que a universidade abrange a transferência de tecnologia e a criação e o desenvolvimento de empresas, passando a ser vista como universidade empreendedora (ETZKOWITZ, 2009). 
Etzkowitz (2009, p.37), sugere que uma universidade empreendedora deve apoiar-se sobre quatro pilares:

I. Liderança acadêmica capaz de formular e implantar uma visão estratégica;

2. Controle jurídico sobre os recursos acadêmicos, incluindo propriedades físicas, como os prédios da universidade e a propriedade intelectual que resulta da pesquisa;

3. Capacidade organizacional para transferir tecnologia por meio de patenteamento, licenciamento e incubação;

4. Um ethos empreendedor entre administradores, corpo docente e estudantes. Conforme Etzkowitz (2009), a universidade poderá atingir os resultados ideais do modelo empreendedor, quando equilibrar as cinco diretrizes: I) capitalização - criando o conhecimento e transmitindo-o para a sociedade; 2 ) interdependência - interagindo com a indústria e o governo; 3) independência - não dependendo de outra esfera institucional; 4) hibridação - criando formatos organizacionais que atinjam os objetivos dos envolvidos; e 5) reflexividade - renovando continuamente as estruturas que permeiam as relações com a indústria e o governo. As alterações do cenário socioeconômico têm resultado em constantes modificações nas atividades científicas das universidades, que estão reestruturando seus núcleos de pesquisa para atender à ampliação da exploração da universidade por parte das empresas (REIS, 2008).

Consoante ao entendimento de Etzkowitz (2009), a atuação de forma cooperativa entre as dimensões governamentais, industriais e acadêmicas expandem o processo inovador no ambiente onde estão inseridas, refletindo na renovação e remodelagem de empresas de diferentes portes e segmentos. Dessa forma, a indústria passa de uma organização isolada para uma entidade da Hélice Tríplice.

Ao perceber que a universidade amplia as ações que a caracterizam como empreendedora no que tange ao desenvolvimento e à comercialização da pesquisa, a indústria passa a identificar a universidade, seja como parceira, concorrente, ou das duas formas (eTzkowitz, 2009). De acordo com Reis (2008), conseguir acesso às fronteiras científicas, aumentar a capacidade de previsão da ciência, delegar atividades de pesquisa e suprir a falta de 
recursos, podem ser alguns dos fatores motivadores para as empresas se relacionarem com as universidades.

Segundo Etzkowitz (2003), pertence ao governo o compromisso de fornecer recursos, financiar pesquisas e fomentar o empreendedorismo organizacional como forma de incentivo à criação de novas empresas. Assim, o modelo de atuação da Hélice Tríplice sugere a consolidação do papel do governo, trabalhando em conjunto com a universidade e com a indústria, projetando as ações de inovação. Quando o governo atua isoladamente nas ações referentes à Hélice Tríplice, as ideias e iniciativas tendem a ser limitadas, pois o governo pode agir incorporando os outros agentes e gerir suas atividades (ETzKOwITz, 2009).

Etzkowitz (2009) defende ainda que o modelo de atuação ideal da Hélice Tríplice seria da seguinte maneira:

A configuração ideal da Hélice Tríplice é aquela em que as três esferas interagem e cada uma assume o papel das outras, sendo que as iniciativas surgem lateralmente bem como de baixo para cima e de cima para baixo. A sociedade civil é a base da hélice tríplice e da relação entre política científica e democracia. Embora uma Hélice Tríplice limitada possa existir em condições autoritárias, uma Hélice Tríplice completa ocorre em uma sociedade democrática onde as iniciativas possam ser livremente formuladas. 


\section{INCUBADORA DE EMPRESAS}

As incubadoras de empresas foram concebidas com base nas iniciativas da Universidade de Standford, que criou um parque industrial e tecnológico ainda na década de 1950. Essa iniciativa, apoiada por sua localização na região conhecida como Vale do Silício, na Califórnia, pretendia transferir as tecnologias desenvolvidas na Universidade às empresas, possibilitando a criação de novas empresas intensivas em tecnologia (MORAIS, 1997).

Na década de 1970, configurou-se a estrutura atualmente apresentada pelas incubadoras, quando nos Estados Unidos e na Europa Ocidental as universidades, governos locais e instituições financeiras se reuniram para promover o processo de industrialização de regiões em declínio ou pouco desenvolvidas. A motivação principal para estas iniciativas era de cunho econômico e social, pois pretendia criar novos postos de trabalho, gerar renda e desenvolvimento econômico para as regiões (MORAIs, 1997).

As incubadoras de empresas constituem um mecanismo que pretende estimular a criação e o desenvolvimento de micro e pequenas empresas industriais ou de prestação de serviços, de base tecnológica ou manufaturas leves. Esse processo é realizado por meio da formação complementar do empreendedor, que, geralmente estão em situação de acadêmicos ou não possuem educação formal (MINISTÉRIO DA CIÊNCIA E TECNOLOGIA, 2000). Para que se possam atingir os objetivos propostos, as incubadoras oferecem aos seus incubados a infraestrutura e o suporte gerencial, orientando seus empreendedores no que diz respeito às questões centrais no desenvolvimento de uma empresa, tais como a gestão do negócio e sua competitividade (Associação Nacional de Entidades Promotoras de Empreendimentos Inovadores - ANPROTEC, 20I3).

De acordo com Etzkowitz, Mello e Almeida (2005), o movimento das incubadoras brasileiras representou uma nova direção da ciência, tecnologia e política industrial latino-americana. Esse movimento surgiu depois do colapso do regime militar e da renovação da sociedade brasileira, ocorridos na década de 1980 , em que a ausência de um projeto centralizado permitiu uma flexibilidade no modelo, aproveitando os 
esforços acadêmicos, recursos industriais e do governo, tornando o programa menos oneroso.

Nos anos 1990, o movimento das incubadoras brasileiras se desenvolveu, atuando como instrumento de superação da crise e de alteração cultural. Nesse contexto, o Relatório Técnico emitido pela ANPROTEC em associação com o Ministério da Ciência, Tecnologia e Inovação no ano de 20 II demonstrou a maturidade atingida pelo movimento das incubadoras brasileiras, visto que as 384 incubadoras em operação abrigam 2.640 empresas, 2.509 empresas graduadas operando individualmente (isto é, que não foram adquiridas por outras empresas) e I.I24 empresas associadas. Esses resultados geram 19.394 postos de trabalho nas empresas incubadas, 29.205 nas empresas graduadas, $\mathrm{R} \$ 533$ milhões em faturamento nas empresas incubadas e $\mathrm{R} \$ 4$, I bilhões em faturamento nas empresas graduadas. O mesmo estudo revelou ainda que $98 \%$ das empresas incubadas inovam, sendo que $28 \%$ com foco no âmbito local, $55 \%$ no nacional e $15 \%$ no mundial. Cabe ressaltar que as empresas graduadas são aquelas que, embora tenham passado pelo processo de incubação, já encerraram suas atividades junto às incubadoras e estão em operação no mercado (ANPROTEC, 20I3).

O processo de incubação de empresas no Brasilé dividido em:i) incubadoras de base tecnológica; ii) incubadoras tradicionais; iii) incubadoras mistas; iv) incubadoras sociais; e v) incubadoras de cooperativas. As incubadoras de base tecnológica compreendem as empresas cujos produtos, processos ou serviços nos quais a tecnologia representa alto valor e agregado, enquanto as incubadoras tradicionais abrigam as empresas de diferentes setores da economia, que queiram agregar valor aos seus produtos, processos ou serviços, mas que utilizam tecnologia largamente difundida. As incubadoras mistas são aquelas que abrigam tanto empreendimentos de base tecnológica como de setores tradicionais da economia e as incubadoras sociais e de cooperativas congregam os empreendimentos oriundos de projetos sociais e associativos (ANPROTEC, 20I3).

Independente de sua área de atuação, as incubadoras precisam garantir aos seus incubados espaço físico individualizado para a instalação de escritórios e laboratórios das empresas admitidas; espaço físico de uso 
compartilhado como sala de reunião, secretaria e serviços administrativos; recursos humanos e serviços especializados para o auxílio das empresas incubadas, tais como contabilidade, assistência jurídica, gestão empresarial e outros; atividades de capacitação, formação e treinamento dos empresários e empreendedores nos principais aspectos gerenciais e acesso a laboratórios e bibliotecas de universidade ou instituições que desenvolvam atividades tecnológicas (MINISTÉRIO DA CIÊNCIA E TECNOLOGIA, 2000).

Dentre as organizações de vinculação das incubadoras, as universidades consistem nas principais instituições, seguidas pelos governos municipais, governos estaduais, organizações não governamentais e entidades empresariais. É possível perceber que as incubadoras vinculadas às universidades apresentam uma gama completa de seus objetivos priorizados, enquanto as demais apresentam ações restritas (ANPROTEC, 2013).

No que tange aos benefícios, sob a óptica das empresas incubadas, o processo surge como a oportunidade de incorporar inovações em seus processos de produção ou prestação de serviços, destacando-se também a redução na mortalidade das empresas. De acordo com os dados obtidos pelo Serviço Brasileiro de Apoio às Micro e Pequenas Empresas (SEBRAE) no ano de 20I3, estimase que $24,4 \%$ das micro e pequenas empresas brasileiras desaparecem antes do segundo ano de existência, tomando-se como base as empresas constituídas no ano de 2007 (SEBRAE, 20I3). Contudo, as estimativas obtidas pela ANPROTEC mostram a redução da taxa de mortalidade das empresas que passam pelo processo de incubação, confirmando as estatísticas americanas e européias que mostram a diminuição deste risco de 70\% para 20\% (ANPROTEC, 20I3).

Para as cidades ou regiões de instalação das incubadoras, os benefícios decorrentes de sua instalação podem ser entendidos como o surgimento de novos negócios e aumento dos postos de trabalho, podendo gerar empregos diretos ou indiretos. Ainda, será possível observar um aumento gradual na arrecadação local de impostos, em longo prazo, na medida em que as empresas deixam a incubadora e passam a participar do mercado como empresas consolidadas.

Ressalta-se que as incubadoras de empresas fomentam o empreendedorismo que, segundo Hisrich e Peters (2004), é uma maneira de conectar a ciência e o 
mercado, com base na criação de novas empresas, com o lançamento de novos produtos e serviços. As incubadoras são facilmente relacionadas às startups, empresas em fase de construção, geralmente com menos de um ano de vida, em que seus produtos e serviços estão sendo melhorados e sua aceitação pelo mercado ainda está sendo avaliada (DORNELAS, 2008).

Assim como as incubadoras de empresas, as startups são relacionadas à pesquisa, investigação e desenvolvimento de ideias inovadoras, compreendendo formas de praticar o empreendedorismo e propiciar o desenvolvimento econômico regional. 


\section{PROCEDIMENTOS METODOLÓGICOS}

\section{AMBIENNCIA DA PESQUISA}

A pesquisa para o desenvolvimento deste estudo foi ambientada na Sociedade Incubadora Tecnológica de Caxias do Sul (ITEC), que tem como objetivo apoiar a formação e consolidação de micro e pequenas empresas tecnologicamente inovadoras, visando o desenvolvimento econômico e social do município. A Incubadora Tecnológica foi criada em março de 1999 com a finalidade de apoiar, fomentar e articular ações efetivas na formação de novas empresas de base tecnológica de maneira a evitar a alta taxa de mortalidade que atinge as novas empresas nos seus primeiros anos de implantação. Essa associação é mantida pela parceria entre a Universidade de Caxias do Sul (UCS), a Prefeitura Municipal de Caxias do Sul e a Câmara de Indústria, Comércio e Serviços de Caxias do Sul.

Foram analisadas quatro ópticas envolvidas neste projeto: Universidade, Poder Público Municipal, Entidade de Classe representativa da indústria e uma empresa graduada da incubadora estudada.

\section{OBJETIVOS}

O objetivo geral desse estudo é identificar como o conceito da Hélice Tríplice está aplicado nas atividades da Sociedade Incubadora Tecnológica de Caxias do Sul.

Para atingir o objetivo geral foram apontados os seguintes objetivos específicos:

A Avaliar como cada dimensão da Hélice Tríplice coopera nas atividades desenvolvidas pela incubadora tecnológica;

B Identificar quais os benefícios obtidos por cada dimensão da Hélice Tríplice nas atividades desenvolvidas pela incubadora tecnológica;

c Descrever as dimensões da Hélice Tríplice, enfatizando a relação universidade-indústria-governo. 


\section{TÉCNICAS E PROCEDIMENTOS APLICADOS}

Neste estudo foi empregada uma técnica de pesquisa que pode ser classificada como pesquisa qualitativa de caráter exploratório (HENNINK; HUTTER; BAILEY, 2OII; REMLER; VAN RYZIN, 20II). Os dados que dizem respeito às instituições estudadas foram obtidos por intermédio de observação direta e de questionamentos aos profissionais de cada instituição que respondem pelas atividades relacionadas à incubadora tecnológica. Foram aplicadas à esses profissionais entrevistas individuais em profunidade, com uma abordagem semiestruturada, mediante a utilização de um roteiro básico de questões (RIBEIRO; MILAN, 2004; KING; HORROCKS, 20IO).

Conforme Cooper e Schindler (2003), reforçado por Ribeiro e Milan (2004) e por King e Horrocks (2010), a entrevista individual em profundidade confere ao entrevistador, como vantagens principais, a possibilidade de abordar itens com maior profundidade, permitindo elevado grau de controle do tempo e maleabilidade para adaptações em determinadas situações.

Segundo King e Horrocks (2010), a abordagem semiestruturada das entrevistas permite aos entrevistados a liberdade para responder cada pergunta com a orientação que julgar conveniente, podendo compartilhar de forma ampla as informações, com base no foco estipulado pelo entrevistador. A condução das entrevistas foi realizada pelas autoras e utilizou-se de um roteiro básico de questões validado por um expert da área de inovação. Cada entrevista individual para aplicação do roteiro de questões apresentou duração média de uma hora, que conforme sugerido por Wolcott (1994), seria tempo suficiente para proporcionar a compreensão das dimensões da Hélice Tríplice identificadas por cada um dos entrevistados.

É oportuno evidenciar que todas as entrevistas realizadas foram gravadas em meio eletrônico e posteriormente transcritas, de acordo com Wolcott (1994) e Ribeiro e Milan (2004), de modo a auxiliar nas atividades de análise e interpretação dos resultados. Cabe ressaltar que a relevância deste processo está na busca de elementos empíricos que contribuam para o atendimento aos objetivos propostos para o estudo.

Para a realização desse trabalho, foram entrevistados, portanto, profissionais com relevante atuação nas atividades que abrangem a ITEC: 
Carlos Renato B. da Silva - Diretor/Gerente da ItEC, Marcelo Nichele - Presidente Conselho Superior ITEC, representando a dimensão da universidade, Orlando Marin - Membro do Conselho Fiscal do Sindicato das Indústrias de Material Plástico do Nordeste Gaúcho, Vice-Presidente do Conselho Diretor da Fundação Universidade de Caxias do Sul e representante da Câmara de Indústria, Comércio e Serviços no Conselho Superior da ITEC, representando a dimensão da indústria, Bruno Sassi Brunelli - Diretor Geral da Secretaria do Desenvolvimento Econômico, Trabalho e Emprego de Caxias do Sul, representando a dimensão governo, e Marcio Slomp - Diretor da empresa Comlink Equipamentos Eletrônicos, representando uma empresa que obteve êxito depois da incubação.

Os dados obtidos pelas pesquisadoras, decorrentes do emprego da técnica de entrevistas individuais em profundidade, normalmente são apresentados em forma de texto. A forma de apresentação da análise destes dados, é geralmente por meio do método análise de conteúdo (ROESCH, 1996). De acordo com os pressupostos encontrados na literatura em relação à análise de conteúdo, a análise dos dados respeitou os presspostos de exaustividade, representatividade, homogeneidade e pertinência (BARDIN, 2004; Bernard; RYAN, 20IO; SCHREIER, 20I2). Por fim, apresenta-se a transcrição dos dados coletados (excertos de entrevistas) em alinhamento com os conhecimentos obtidos dos autores que embasaram cientificamente o estudo, proporcionando uma melhor compreensão dos assuntos tratados. 


\section{ANÁLISE E INTREPRETAÇÃO DOS RESULTADOS}

A metodologia proposta para este estudo exigiu a coleta de informações referentes ao funcionamento da Sociedade Incubadora Tecnológica de Caxias do Sul, com a finalidade de entender as ações e benefícios dessa associação. Esses dados serão agora apresentados e, na sequência, explicitamse os resultados obtidos por meio da investigação de cada um dos envolvidos nesse processo.

A Sociedade Incubadora Tecnológica de Caxias do Sul, uma associação sem fins lucrativos, começou suas atividades atendendo seis empresas. Essa sociedade foi fundada pela Universidade de Caxias do Sul, Prefeitura Municipal de Caxias do Sul e Câmara de Indústria, Comércio e Serviços de Caxias do Sul - CIC, utilizando os moldes de outras incubadoras de empresas instaladas no Brasil. Assim, constituiu-se a primeira iniciativa formalizada da Hélice Tríplice na cidade de Caxias do Sul.

Para a construção do espaço físico da Incubadora Tecnológica, foram utilizados recursos financeiros do Governo do Estado do Rio Grande do Sul, em parceria com os agentes responsáveis pela fundação da Incubadora. A Universidade de Caxias do Sul cedeu o terreno onde a sociedade se instalou, a Prefeitura Municipal de Caxias do Sul forneceu a terraplanagem da área e a Cic providenciou o mobiliário necessário. A partir de 2003, houve uma reformulação na gestão da Incubadora Tecnológica, tornando-a menos burocrática e, com base nesta modificação, a mesma conseguiu se consolidar e alcançar êxito.

Atualmente, a Incubadora Tecnológica oferece às empresas incubadas o espaço físico de instalação e os serviços de recepção, telefonia, limpeza, estacionamento e câmeras de segurança, cujos custos são divididos entre as empresas incubadas. Além disso, os incubados têm acesso à sala de reuniões, cursos de capacitação e consultorias e acesso facilitado às bibliotecas e laboratórios da Universidade de Caxias do Sul. A capacidade atual de atendimento da incubadora é de 12 empresas, que podem permanecer incubadas pelo período de dois anos, prorrogável por mais um ano. O número de empresas já graduadas pela incubadora é de 35 empresas. 
A gestão da Incubadora Tecnológica é realizada por meio de um Conselho Superior, composto por membros da Universidade de Caxias do Sul, Prefeitura Municipal e Câmara de Indústria, Comércio e Serviços de Caxias do Sul. O quadro funcional conta com um Gerente, uma Assessora Executiva e uma funcionária responsável pela higienização do local.

\section{AÇÕES DE CADA DIMENSÃO DA HÉLICE TRÍPLICE}

No entendimento de Etzkowitz e Leydesdorff(2000), o modelo da Hélice Tríplice contempla ações da Universidade, enquanto promotora do relacionamento com as empresas, e do Governo, que atua como regulador e fomentador das atividades econômicas. Desta forma, a Sociedade Incubadora Tecnológica de Caxias do Sul surgiu como iniciativa formalizada do modelo Hélice Tríplice, pois relaciona as ações da Universidade de Caxias do Sul, da Prefeitura Municipal e da Câmara de Indústria, Comércio e Serviços, a fim de fortalecer o desenvolvimento econômico da região e fomentar a inovação tecnológica.

A Universidade de Caxias do Sul constitui-se, atualmente, como a mais antiga Instituição de Ensino Superior da Região Nordeste do Rio Grande do Sul e, por ter sido construída pelo esforço coletivo da comunidade, tem seus interesses voltados para o bem estar da coletividade e para o desenvolvimento econômico regional (UCS, 20I3). A implantação da incubadora tecnológica, nesse contexto, constituiu-se como uma oportunidade de incentivar a inovação tecnológica no setor privado da cidade, tornando público o conhecimento acadêmico.

Ao longo dos anos, a Universidade de Caxias do Sul buscou sua inserção no cenário nacional como uma universidade com orientação para os programas de inovação, de tal forma que foi a primeira Instituição do Rio Grande do Sul a constituir uma Pró-Reitoria e Coordenadoria de Inovação em sua estrutura. O planejamento futuro da instituição prevê a implantação de Incubadoras Tecnológicas em cada uma das nove cidades onde possui atuação, utilizando-se o modelo de êxito obtido na Sociedade Incubadora Tecnológica de Caxias do Sul.

Com relação à sua atuação na Incubadora Tecnológica, a ucs participa com $40 \%$ dos recursos financeiros que mantém a sociedade, além de responsabilizar-se pelos serviços de iluminação, conservação da área e vigilância externa das instalações físicas. Além disso, as empresas incubadas 
têm acesso livre ao sistema de bibliotecas da Universidade e valor reduzido para a utilização dos laboratórios, a fim de incentivar o emprego de alta tecnologia em seus processos ou produtos.

A principal contribuição da Universidade para as empresas incubadas, contudo, diz respeito ao auxílio na captação de recursos e registro de patentes. De acordo com a Coordenadoria de Inovação e Desenvolvimento Tecnológico da ucs, grande parte dos problemas relacionados ao registro de patentes refere-se à falta de conhecimento na formulação destas. Assim, as patentes geradas com base nos produtos desenvolvidos na incubadora são descritas com o auxílio de profissionais da instituição, o que ajuda a reduzir os erros ocasionados pela má formulação. Já com relação à captação de recursos, a Universidade atua como incentivadora e fomentadora na procura por incentivos de órgãos governamentais.

Considerando-se a atuação da ucs junto às empresas incubadas, é possível perceber o comportamento de uma Universidade empreendedora, que, de acordo com Etzkowitz (2009), deve apoiar-se sobre os pilares da liderança acadêmica, controle jurídico sobre os recursos acadêmicos, capacidade organizacional para transferir tecnologia e um ethos empreendedor entre a administração, corpo docente e discente.

Ainda de acordo com Etzkowitz (2009), na medida em que a Universidade amplia sua atuação como instituição empreendedora, a indústria passa a identificá-la como parceira, concorrente ou de ambas as formas. Nesse sentido, por meio da relação institucionalizada com a fundação da Incubadora Tecnológica, a Universidade de Caxias do Sul passou a atuar como parceira do setor industrial caxiense, pois seu intuito é promover o crescimento do setor tecnológico e, por conseguinte, o desenvolvimento econômico da região.

A Câmara de Indústria, Comércio e Serviços de Caxias do Sul, por sua vez, representa a dimensão da indústria no modelo da Hélice Tríplice constituído por meio da Incubadora Tecnológica. Atualmente, a cic de Caxias do Sul é a maior e mais expressiva entidade de classe do interior do estado, congregando pessoas jurídicas que exercem atividades empresariais na Região Nordeste do Rs (CIC, 20I3). De acordo com sua missão, pretende liderar 
a classe empresarial de forma inovadora, fortalecendo a livre iniciativa e o desenvolvimento sustentável da região, razões que propiciaram a interação com os demais agentes da Hélice Tríplice na implantação da incubadora.

Embora a participação da cIC na manutenção da incubadora, por meio de recursos financeiros, tenha sido tão expressiva quanto à dos demais agentes no início das atividades, a partir do ano de 201 a cic diminuiu sua participação no fomento das atividades, colaborando com $20 \%$ dos recursos da sociedade. Essa diminuição se deu pelo fato de que, dos I3 sindicatos associados à CIC, somente 02 sindicatos optaram pela continuidade do investimento na Incubadora, pois acreditam que os resultados poderão ser visualizados no longo prazo. Outro serviço prestado pela CIC à Incubadora é a apuração contábil, que é realizada dentro da Câmara.

É importante ressaltar que, dentre as empresas incubadas e graduadas pela Incubadora Tecnológica de Caxias do Sul, encontra-se expressiva participação nos setores de desenvolvimento de softwares e sistemas informatizados, em detrimento de outros segmentos igualmente importantes para o desenvolvimento do setor empresarial caxiense, como por exemplo, os setores metalúrgico e plástico, indústria do vestuário, entre outros. Para a cic, o ideal seria que outros segmentos fossem atendidos de forma direta, contribuindo para o crescimento da classe empreendedora em Caxias do Sul.

Essa visão da cic caxiense está relacionada ao entendimento de Etzkowitz (2009), no sentido de que a atuação de forma cooperativa dos agentes deve expandir o processo inovador no ambiente onde estão inseridas, refletindo na renovação e remodelagem de empresas de diferentes portes e segmentos. Somente desta forma, segundo complementa o autor, a indústria passa de uma organização isolada para uma entidade da Hélice Tríplice.

A atuação do Poder Público Municipal na Itec é realizada por meio da Secretaria do Desenvolvimento Econômico, Trabalho e Emprego de Caxias do Sul. Além da participação efetiva no Conselho Superior da incubadora, a Secretaria participa com $40 \%$ dos recursos financeiros recebidos pela incubadora, além do apoio nas atividades realizadas na associação para o surgimento e manutenção de novas empresas. 
De acordo com o entendimento de Etzkowitz (2003), o governo deve fomentar o empreendedorismo organizacional por meio do financiamento de pesquisas e o fornecimento de recursos. Nesse sentido, o Poder Público Municipal de Caxias do Sul acredita que o fomento às iniciativas de inovação da Universidade é a melhor forma de desenvolver a transferência de tecnologia para o setor privado, pois, de certa forma, a tecnologia produzida na Universidade chegará ao conhecimento da sociedade somente por meio do setor privado. Por isso, a maior atuação do Poder Público Municipal ocorre no sentido de incentivar o crescimento da incubadora, a fim de que ela atinja cada vez mais segmentos e forme, a cada dia, mais empresas maduras para o mercado.

\section{BENEFÍCIOS E VANTAGENS IDENTIFICADAS POR CADA DIMENSÃO DA HÉLICE TRÍPLICE}

Ainda que a participação na implantação da Sociedade Incubadora Tecnológica de Caxias do Sul tenha constituído o primeiro modelo formalizado da Hélice Tríplice na cidade, cada participante desse processo precisa identificar, separadamente, os benefícios e vantagens obtidas com a criação da associação. Desta forma, as entrevistas realizadas investigaram de que forma os agentes se beneficiam com a instituição da incubadora e com o relacionamento ocorrido entre os próprios agentes.

Dentre os benefícios obtidos pela Universidade de Caxias do Sul pode-se citar o retorno do investimento realizado, que, avaliando-se individualmente uma empresa incubada, sem projetos em conjunto, o retorno é de aproximadamente $36 \%$ do valor investido. Mas se houver um projeto em conjunto, como um edital, o retorno pode alcançar $65 \%$ do investimento. E se o projeto for um desenvolvimento direto, o retorno pode superar $100 \%$ do investimento da ucs. O principal benefício citado pela universidade é em forma de incentivo à pesquisa científica, pois inúmeras empresas que se instalaram na Incubadora Tecnológica utilizaram conhecimentos e técnicas obtidos na academia, devolvendo esse investimento à instituição em forma de patentes formalizadas. Até o momento da realização desta investigação, foram sete as patentes geradas na ITEC, sendo seis apoiadas pela 
ITEC/UCs e uma realizada diretamente pela empresa incubada. Isso se torna um grande incentivo aos pesquisadores da área de tecnologia e inovação da Universidade, visto que as patentes podem ser entendidas como o êxito nas pesquisas realizadas.

Além disso, como as empresas incubadas possuem acesso facilitado aos laboratórios e às bibliotecas da instituição, cria-se um vínculo e um relacionamento de confiança entre os parceiros, o que, algumas vezes, acaba trazendo novos alunos para a instituição, em busca de capacitação para a atividade empreendedora iniciada na incubadora. O caso exitoso da própria incubadora, por exemplo, está servindo como modelo para a implantação de incubadoras tecnológicas em outras cidades de atuação da UCs, como Bento Gonçalves e São Sebastião do Caí.

Outro benefício citado pela instituição de ensino é a facilidade de, por meio da incubadora tecnológica, aumentar a atuação do setor de inovação da universidade, com a criação do Parque Tecnológico da Universidade de Caxias do Sul (Tecnoucs). Ainda, segundo os entrevistados, a presença da incubadora promove visibilidade e destaque para a Universidade, que se consolida não somente como a mais antiga instituição de ensino superior da região Nordeste do Rio Grande do Sul, mas também, como uma Universidade inovadora, empreendedora e tecnológica.

Esse reconhecimento traz para a ucs benefícios na conquista de novos alunos e no fomento das instituições governamentais aos seus projetos tecnológicos, o que resulta na consolidação de um ciclo ininterrupto de parceria e colaboração. Um dos maiores exemplos dessa área é que a empresa ComLink, que participou dessa pesquisa representando as empresas graduadas pela incubadora, inscreveu-se em um edital para o recebimento de equipamentos de alta tecnologia para o desenvolvimento de pesquisas. Contudo, esses equipamentos deveriam ser repassados a uma instituição de ensino, após a utilização dos mesmos. Desta forma, os equipamentos foram doados à ucs com a exigência de que fossem repassados à Incubadora, para que o ciclo de parcerias continuasse se consolidando na prática, e não somente na teoria.

Sob a ótica da cIc, a incubadora tecnológica torna-se um instrumento 
valioso, pois capacita as empresas e empreendedores da cidade, gerando para o mercado organizações maduras e bem constituídas, que tendem a acelerar o crescimento econômico da região. De acordo com os dados obtidos pela ITEC, das 36 empresas que passaram pelo processo de incubação, 35 estão atuando no mercado de forma individual ou foram adquiridas por outras empresas, e uma empresa encerrou suas atividades por vontade do empresário, e não pelas suas condições de competitividade. Assim, a incubadora tecnológica apresenta um índice de $97 \%$ de sucesso para o desenvolvimento de empresas. Ainda, para a entidade de classe, a capacitação dos inventores - transformando-os em empreendedores - é a força motriz para a manutenção do setor industrial caxiense, tradição trazida pelos imigrantes italianos e fortemente arraigada na região.

Já as empresas que participam do processo de incubação, sob a visão da empresa graduada entrevistada, obtêm como benefícios a diminuição dos custos iniciais de operação com status de empresa organizada, auxílio e facilidade no acesso às informações administrativas e contábeis, capacitação dos empreendedores e consultoria de especialistas das áreas, bem como o auxílio constante da gerência da ITEC que, ao perceberem as dificuldades das empresas e do mercado, sugerem oportunidades de pesquisa e desenvolvimento para os incubados. Esses fatores geram capacidade de desenvolvimento e maturidade em empresas recém-constituídas, abrindo as portas do mercado para os pequenos empreendimentos e criando vínculos e parcerias que se tornarão importantes no desenvolvimento futuro.

Já sob o ponto de vista do Poder Público Municipal, a Incubadora Tecnológica atua de forma decisiva no desenvolvimento econômico da cidade, ainda que essa relação não possa ser expressa de forma estatística por não haver dados suficientes para demonstrar esta relação. As estimativas obtidas pela ANPROTEC (2013) mostram uma redução da taxa de mortalidade das empresas brasileiras que passam pelo processo de incubação, e as estatísticas americanas e estrangeiras mostram que esse risco diminui de $70 \%$ para $20 \%$. Acredita-se que esta situação ocorra no mercado caxiense em razão dos dados de empresas incubadas e graduadas informados anteriormente, onde apenas uma das empresas incubadas pela ITEC não está 
em atividade atualmente. Para o Poder Público Municipal, o maior benefício obtido com a presença da Incubadora Tecnológica é justamente, a redução do risco de mortalidade das empresas nos primeiros anos de funcionamento, visto que das empresas incubadas, somente uma não completou o processo de incubação, pela desistência do próprio empreendedor.

Outros benefícios identificados pelo governo são a geração e manutenção de mais empregos, a adequada capacitação dos profissionais, o desenvolvimento das iniciativas tecnológicas, o apoio do governo nas esferas estadual e federal para a captação de recursos a serem investidos em inovação tecnológica, dentre outros. Além disso, a formação de novas empresas gera, indiretamente, o recolhimento de mais impostos pelo município, recurso que será reinvestido na Incubadora, alimentando o ciclo ininterrupto já mencionado.

\section{RELAÇÃO ENTRE AS DIMENSÕES DA HÉLICE TRÍPLICE}

O Triângulo de Sábato, proposto por Sábato e Botana (1968), propunha um modelo baseado na ação múltipla e coordenada entre o governo, a estrutura produtiva e a infra estrutura científica e tecnológica. A evolução dos estudos levou ao conceito da Hélice Tríplice de Etzkowitz (2009), mantendo-se, contudo, a proposta de interação inicial.

$\mathrm{Na}$ fundação da Sociedade Incubadora Tecnológica de Caxias do Sul, os agentes envolvidos buscaram, inicialmente, a formalização do conceito da Hélice Tríplice. Contudo, ao longo de quase I4 anos de existência, eles acreditam que a incubadora deva tornar-se uma sociedade auto-sustentável, no sentido de que as atividades da incubadora não dependam exclusivamente de incentivos dos agentes envolvidos.

Desta forma, buscando gerar autonomia para a sociedade e atuando somente como órgão consultivo, o Conselho Superior da ITEC reúne-se a cada três ou quatro meses, a fim de alinhar os objetivos da organização e solucionar questões pontuais. É realizada também uma Assembléia Anual, onde são apresentadas as projeções das próximas atividades.

A Universidade de Caxias do Sul tem um relacionamento estreito com a Incubadora não somente pela proximidade das instalações físicas, mas 
principalmente pelas ações realizadas em conjunto com a Prefeitura Municipal. Ou seja, como ambas as instituições atuam em conjunto nos Arranjos Produtivos Locais, nas questões relacionadas à Habitação e Desenvolvimento Sustentável do Município, a facilidade de contato entre os representantes torna as discussões acerca da Incubadora Tecnológica uma constante neste relacionamento. Já no que diz respeito à cic, a entidade faz parte do Conselho Diretor da Fundação Universidade de Caxias do Sul, mantenedora da instituição de ensino, o que ocasiona uma aproximação e favorece o relacionamento entre os agentes.

De acordo com o posicionamento dos entrevistados, a criação do Parque Tecnológico da ucs (Tecnoucs), prevista inicialmente para ser completada até o final do ano de 2013, irá gerar mais oportunidades e investimentos para o desenvolvimento da região e, por conseguinte, da Incubadora Tecnológica. Assim sendo, a implantação do Tecnoucs tende a aumentar o dinamismo da relação entre os agentes da Hélice Tríplice que atuam na Incubadora, fortalecendo a sociedade e auxiliando no desenvolvimento tecnológico da região. 


\section{CONSIDERAÇÕES FINAIS}

Embora o modelo da Hélice Tríplice esteja intrinsecamente conectado ao conceito de inovação tecnológica, e as incubadoras de empresas sejam parte da formalização deste modelo, a criação de um Sistema de Inovação no Brasil ainda é um cenário utópico, considerando-se o distanciamento entre a Universidade e o setor industrial. Assim, os sistemas e produtos inovadores que são concebidos na academia encontram barreiras no momento de sua transição para o setor privado, impedindo a popularização da ciência brasileira. Essa falta de vínculo impede ainda que as micro e pequenas empresas tomem conhecimento dos incentivos financeiros oferecidos à pesquisa em inovação pelas agências de fomento, dificultando o processo de inovação tecnológica brasileiro.

Assim, a criação da Sociedade Incubadora Tecnológica de Caxias do Sul pode ser entendida como a oportunidade de criar a ligação entre a academia e o setor industrial na região, desenvolvendo a produção científica local e representando a iniciativa necessária para criação de um Sistema de Inovação. Após esse movimento, a universidade pode ser identificada como uma nova fonte de produção de informação e conhecimento, promovendo a propagação da ciência, da tecnologia e da inovação.

Ao analisar a perspectiva dos agentes responsáveis pela fundação e manutenção da Incubadora Tecnológica de Caxias do Sul é possível perceber que o conceito Hélice Tríplice não é somente um modelo formalizado, mas principalmente uma forma de atuação e de interação entre os agentes. Isso pode ser observado por meio dos benefícios que são percebidos pelos envolvidos no processo, bem como, pela clareza com que exercem sua atuação, respeitando o espaço de atuação do outro.

Com a realização deste estudo, verificou-se que a Incubadora Tecnológica constituída em Caxias do Sul não somente atingiu seu objetivo inicial, de promover a inovação tecnológica e disseminar o conhecimento para os empresários, como também devolve aos seus investidores e à comunidade caxiense o investimento financeiro que obtém, por meio da maturidade das empresas que estão no mercado caxiense, da geração de patentes e da redução 
na mortalidade das empresas. Ainda assim, o setor industrial percebe uma inconsistência entre as invenções desenvolvidas pelos pesquisadores da instituição e os produtos e processos oferecidos ao mercado, ressaltando que muitos segmentos industriais não possuem quaisquer investimentos no âmbito da Incubadora.

Desta forma, apesar dos agentes que fazem parte do modelo Hélice Tríplice atuarem de forma coordenada e participativa, visto que a incubadora gera resultados positivos e satisfatórios para a sociedade, ainda há a possibilidade de melhorar a sociedade formalizada, permitindo a incubação de mais empresas e o atendimento de outros segmentos da sociedade.

Para futuros estudos, sugere-se um estudo aprofundado acerca das Incubadoras Tecnológicas localizadas no Estado do Rio Grande do Sul, a fim de compará-las no que diz respeito à aplicação do conceito da Hélice Tríplice. Ainda, podem ser realizados estudos no sentido de relacionar a quantidade de patentes registradas pelas Universidades em parceria com as Incubadoras Tecnológicas, investigando a relação entre o número de patentes registradas e a quantidade de empresas graduadas pela Incubadora. 


\section{REFERÊNCIAS}

ASSOCIAÇÃO NACIONAL DE ENTIDADES PROMOTORAS DE EMPREENDIMENTOS INOVADORES - ANPROTEC. Brasília, 2013. Disponível em: $<$ http://anprotec.org.br/site/pt/incubadoras-e-parques/>. Acesso em: 25/08/2013.

BARBIERI, J. C. (Org.). Organizações inovadoras: estudos e casos brasileiros. Rio de Janeiro: FGV, 2003.

BARDIN, L. Análise de conteúdo. 3.ed. Lisboa: Edições 70, 2004.

BENNEWORTH, P.; DAWLEY, S. Managing the university third strand innovation process? Developing innovation support services in regionally engaged universities. Knowledge, Technology \& Policy, v. 18, n. 3, p. 74-94, 2005.

BERNARD, H. R.; RYAN, G. W. Analyzing qualitative data: Systematic approaches. Thousand Oaks: Sage Publications, 2010.

CÂMARA DE INDÚSTRIA E COMÉRCIO E SERVIÇOS DE CAXIAS DO SUL - CIC. Caxias do Sul, 2013. Disponível em: $<\underline{\text { http: } / / \text { www.cic-caxias.com.br/institucional/ }}$ apresentacao.asp >. Acesso em: 25/08/2013.

COOPER, D. R.; SCHINDLER, P. S. Métodos de pesquisa em administração. 7.ed. Porto Alegre: Bookman, 2003.

CHRISTENSEN, C. M. O dilema da inovação: Quando novas tecnologias levam empresas ao fracasso. São Paulo: Makron Books, 2001.

CHRISTENSEN, C. M; ANTHONY, S. D.; ROTH, E. A. O futuro da inovação: usando as teorias da inovação para prever mudanças no mercado. Rio de Janeiro: Elsevier, 2007.

DONADIO, L. Política científica e tecnológica. In: MARCOVICH, Jaques. Administração em Ciência e Tecnologia. São Paulo: Edgar Bluscher, 1983.

DORNELAS, J. C. A. Empreendedorismo: Transformando idéias em negócios. Rio de Janeiro: Elsevier, 2008.

ETZKOWITZ, H. Innovation in innovation: The Triple Helix of university-industrygovernment Relations. Social Science Information, v. 42, n. 3, p. 293-337, 2003.

ETZKOWITZ, H. Hélice Tríplice: Universidade-indústria-governo: inovação em movimento. Porto Alegre: EDIPUCRS, 2009.

ETZKOWITZ, H.; LEYDESDORFF, L. The dynamics of innovation: From national systems and "Mode 2" to a Triple Helix of university-industry-government relations. Research Policy February, v. 29, p. 109-123, 2000.

ETZKOWITZ, H.; MELLO, J. M. C.; ALMEIDA, M. Towards “meta-innovation" in Brazil: The evolution of the incubator and the emergence of a triple helix. Rio de Janeiro: Elsevier, 2005.

HENNINK, M.; HUTTER, I.; BAILEY, A. Qualitative research methods. Thousand Oaks: Sage Publications, 2011. 
HISRICH, R. D.; PETERS, M. P. Empreendedorismo. 5.ed. Porto Alegre: Bookman, 2004.

KING, N.; HORROCKS, C. Interviews in qualitative research. Thousand Oaks: Sage Publications, 2010.

PRESIDÊNCIA DA REPÚBLICA CASA CIVIL. Lei no 10.973, 2 de Dezembro de 2004. Disponível em: < http://www.planalto.gov.br/ccivil 03/ ato2004-2006/2004/lei/ 110.973.htm $>$. Acesso em: 25/08/2013.

MINISTÉRIO DA CIÊNCIA E TECNOLOGIA. Manual para a Implantação de Incubadoras de Empresas. Brasília, 2000. Disponível em: < http://www.ufal.edu.br/ empreendedorismo/downloads/manual-para-implantacao-de-incubadoras-deempresas-mct-pni >. Acesso em: 25/08/2013.

MORAIS, E. F. C. A Incubadora de empresas como fator de inovação tecnológica em pequenos empreendimentos. 1997. Dissertação (Mestrado) - Curso de Sociologia, Universidade de Brasília - UnB, Brasília, 1997.

ORGANIZAÇÃO PARA A COOPERAÇÃO E O DESENVOLVIMENTO ECONÔMICO - OCDE. Manual de Oslo: Diretrizes para coleta e interpretação de dados sobre inovação. 3.ed. 2005. Disponível em: <http://www.mct.gov.br/upd_ blob/0026/26032.pdf>. Acesso em: 25/08/2013.

ORGANIZAÇÃO PARA A COOPERAÇÃO E O DESENVOLVIMENTO ECONÔMICO - OCDE. Manual de Frascati: Metodologia proposta para a definição da investigação e desenvolvimento experimental, 2002. Disponível em: $<\underline{\text { http: } / / \text { www.mct. }}$ gov.br/upd blob/0006/6562.pdf > . Acesso em: 23/07/2013.

PLONSKI, G. A. Cooperação empresa-universidade no Brasil: um novo balanço prospectivo. Brasília: IBICT: IEL, 1998.

PORTER, M. E. Vantagem competitiva. Rio de Janeiro: Campus, 1991.

REIS, D. R. Gestão da inovação tecnológica. 2.ed. Barueri/SP: Manole, 2008.

REMLER, D. K.; VAN RYZIN, G. G. Research methods in practice: Strategies for description and causation. Thousand Oaks: Sage Publications, 2011.

RIBEIRO, J. L. D.; MILAN, G. S. Planejando e conduzindo entrevistas individuais. In: RIBEIRO, J. L. D.; MILAN, G. S. (Eds.). Entrevistas individuais. Porto Alegre: FEEng/ UFRGS, 2004.

ROESCH, S. M. A.; MELLO, M. I. Projetos de estágio do curso de administração: Guia para pesquisas, projetos, estágios e trabalho de conclusão de curso. São Paulo: Atlas, 1996.

SÁBATO, J.; BOTANA, N. La ciência y la tecnologia em el desarrollo futuro da America Latina. Revista de la Integracion, v.3, n.1, p. 15-26, 1968.

SERVIÇO BRASILEIRO DE APOIO ÀS MICRO E PEQUENAS EMPRESAS - SEBRAE. Sobrevivência das Empresas no Brasil. Brasília/DF, 2013.

SCHUMPETER, J. A. Teoria do desenvolvimento econômico: Uma investigação sobre lucros, capital, crédito, juro e o ciclo econômico. São Paulo: Nova Cultural, 1985. 
SCHREIER, M. Qualitative content analysis in practice. London: Sage Publications, 2012.

SIQUEIRA, L. C. Inserção de políticas de propriedade intelectual nas instituições de ensino superior: O caso PUC-Rio. 2007. Disponível em <http://www.anpad.org.br/evento. php?acao $=$ subsecao $\&$ cod_edicao_subsecao $=280 \&$ cod_evento_edicao $=33 \& \operatorname{cod}$ _ edicao_trabalho $=7440>$. Acesso em: 25/08/2013.

SNELL, B. Administração: Novo cenário competitivo. 2.ed. São Paulo: Atlas, 2006.

TIDD, J.; BESSANT, J.; PAVITT, K. Gestão da Inovação. Porto Alegre: Bookman, 2008.

UNIVERSIDADE DE CAXIAS DO SUL - UCS. Caxias do Sul, 2013. Disponível em:

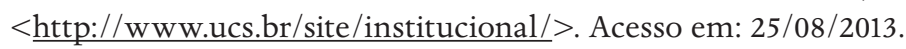

WOLCOTT, H. F. Transforming qualitative data: Description, analysis, and interpretation. Thousand Oaks: Sage Publications, 1994.

ZEN, A. C.; POSSAS, P. H.; SANTIN, B. A Ampliação dos Limites da Universidade por Intermédio da Cooperação com o Setor Produtivo: O caso da Universidade Federal do Rio Grande do Sul. In: EnANPAD, 30., 2006, Salvador. Anais... Salvador: Anpad, 2006. 


\section{DADOS DOS AUTORES}

\section{PRISCILA BRESOLIN TISOTT ${ }^{\star}$ priscila.tisott@gmail.com}

Bacharel em Comércio Internacional pela UCS

Instituição de vinculação: Universidade de Caxias do Sul

Caxias do Sul/RS - Brasil

Áreas de interesse em pesquisa: Gestão de operações e inovação.

${ }^{\star}$ Rua Francisco Getúlio Vargas, 1130 - Bloco F / PPGA

Petrópolis Caxias do Sul/RS 95070-560

DANIELE NESPOLO dani.nespolo@ibest.com.br Especialista em Gestão Empresarial pela UNISINOS

Instituição de vinculação: Universidade de Caxias do Sul Caxias do Sul/RS - Brasil

Áreas de interesse em pesquisa: Marketing, marketing de relacionamento, inovação e empreendedorismo.

\section{DEISE TAIANA DE ÁVILA DIAS deiset.dias@gmail.com}

Bacharel em Administração com Ênfase em Gestão de Negócios pela FSG

Instituição de vinculação: Universidade de Caxias do Sul

Caxias do Sul/RS - Brasil

Áreas de interesse em pesquisa: Modelos mentais, empreendedorismo, Ensino em

Administração, tecnologia e inovação.

\section{PELAYO MUNHOZ OLEA pelayo.olea@gmail.com}

Doutor em Administração pela Universitat Politècnica de Catalunya

Instituição de vinculação: Universidade de Caxias do Sul

Caxias do Sul/RS - Brasil

Áreas de interesse em pesquisa: Inovação, Gestão ambiental e Métodos de Pesquisa em

Administração.

\section{GABRIEL SPERANDIO MILAN gsmilan@ucs.br}

Doutor em Engenharia de Produção pela UFRGS

Instituição de vinculação: Universidade de Caxias do Sul

Caxias do Sul/RS - Brasil

Áreas de interesse em pesquisa: Estratégias de marketing, marketing de relacionamento e estratégias e operações em serviços. 